\title{
Simulating larval dispersal processes for abalone using a coupled particle-tracking and hydrodynamic model: implications for refugium design
}

\author{
Yoichi Miyake ${ }^{1, *}$, Shingo Kimura ${ }^{1}$, Tomohiko Kawamura ${ }^{1}$, Toyomitsu Horiii ${ }^{2}$, \\ Hiroaki Kurogi ${ }^{2}$, Takashi Kitagawa ${ }^{1}$ \\ ${ }^{1}$ Ocean Research Institute, University of Tokyo, 1-15-1 Minamidai, Nakano-ku, Tokyo 164-8639, Japan \\ ${ }^{2}$ National Research Institute of Fisheries Science, Fisheries Research Agency, 6-31-1 Nagai, Yokosuka, Kanagawa 238-0316, Japan
}

\begin{abstract}
A coupled particle-tracking and hydrodynamic model, into which observed current data were assimilated, was used to simulate larval dispersal of large abalone (Haliotis discus discus, H. gigantea, and H. madaka) in Sagami Bay, Japan. The aims of this study were to (1) clarify larval dispersal processes and settlement sites, and (2) evaluate the existing harvest refugium and estimate the suitability of other areas for larval sources, using this model. In the larval dispersal simulations, particles were released at the time of hatching, which was calculated from the estimated time of fertilization/potential spawning and based upon the water temperature. The results of larval dispersal simulations indicate 2 different dispersal patterns: (1) transport toward the coast after dispersal offshore, and (2) gradual dispersal offshore. The refugium was compared with 3 hypothetical reproductive sources located $1 \mathrm{~km}$ north, west, and south of the refugium. During settlement competency, transport success (transport to the area at the depth of adult habitat: $\leq 30 \mathrm{~m}$ ) of particles released at the refugium was highest ( 27 to $75 \%$ ), and suggested that the location of this refugium was more suitable for a larval source than those of the hypothetical reproductive sources. Multiple potential larval settlement sites were identified. These results have important implications for refugium design at the study site. The method and model developed in the present study could be used for evaluating harvest refugia and for identifying effective locations for reproductive sources and potential settlement sites.
\end{abstract}

KEY WORDS: Larval dispersal - Refugia - Marine reserves - Numerical modeling · Abalone · Hydrodynamics

Resale or republication not permitted without written consent of the publishe

\section{INTRODUCTION}

Many marine benthic species have planktonic stages in their life cycle. The exchange of individuals among populations primarily occurs at this time (Cowen \& Sponaugle 2009). When the populations are depleted, larval dispersal plays an important role in the replenishment through recolonization (Tegner \& Butler 1985). Abalone species (Haliotis spp., Haliotidae, Mollusca) have a lecithotrophic (non-feeding) larval stage lasting at least a few days before becoming competent to settle at the bottom (e.g. Takami et al. 2002). Larval dispersal takes place during this period. Two different dispersal processes have been suggested. The first process assumes local larval dispersal near the natal population (Prince et al. 1987, 1988, McShane et al. 1988). The second process assumes passive transport by currents or a concentration in eddies (Itosu \& Miki 1983, Tegner \& Butler 1985, Tanaka et al. 1986, Shepherd et al. 1992, Stephens et al. 2006). Shepherd \& Brown (1993) stated that the difference in dispersal might be due to differences in larval behavior between species or local coastal hydrodynamics.

For broadcast spawners with small home ranges, marine reserves are expected to increase spawning potential within them and are thought to be particularly beneficial (Wallace 1999). However, the reserves must be designed (Stockhausen \& Lipcius 2001, Shanks et al. 2003) and evaluated (Wallace 1999, Lipcius et al. 2001) with quantitative methods. One of the methods is the 
use of coupled particle-tracking and hydrodynamic models, which have been applied to simulate larval dispersal of various marine organisms (e.g. Hinrichsen et al. 2003, Brown et al. 2004, North et al. 2008) and to investigate the efficacy of marine reserves (Lipcius et al. 2001). In the present study, we assessed the effectiveness of refugium locations for larval sources of abalone and investigated potential settlement sites by simulating larval dispersal processes with a coupled particletracking and 3-dimensional hydrodynamic model, into which observed current data were assimilated.

Three large abalone species (Haliotis discus discus, $H$. gigantea and $H$. madaka) and a smaller species $(H$. diversicolor) are found in Sagami Bay, and have been commercially fished. The 3 large species have been drastically reduced since the mid-1980s (Takiguchi 2002). Three harvest refugia $\left(5173.5 \mathrm{~m}^{2}, 6602 \mathrm{~m}^{2}\right.$, and $13197.5 \mathrm{~m}^{2}$; N. Takiguchi pers. comm.) are located in Nagai, Kanagawa (see Fig. 1). Relatively high densities of adult abalone have been established in the refugia by releasing artificial seeds, but the catch in Nagai has not recovered (Takiguchi 2002). The problem may be related to the dispersal of larvae from these reproductive sources. The dispersal processes and settlement sites of larvae from these sources are unknown. Additionally, the spawning cues of these large abalone species are unclear. Therefore, monitoring larval occurrence and dispersal on the basis of regional hydrodynamics is critical for the management of the organisms in this area. In the main refugium $\left(5173.5 \mathrm{~m}^{2}\right)$, the large abalone population consists of $45 \% \mathrm{H}$. discus discus, $41 \% \mathrm{H}$. gigantea, and $14 \%$ H. madaka (percentages are exclusive of unidentified individuals), and the mean adult density (1.96 ind. $\mathrm{m}^{-2}$ ) is at least 3.5 times higher than the rest of the area, including other refugia ( $\mathrm{N}$. Takiguchi pers. comm.). In the present study, larval dispersal of these large abalone species on the east side of Sagami Bay was simulated. Since the reproductive sources outside the main refugium do not seem influential, we only considered the larval dispersal from the main refugium.

Duration of the larval stage and larval behavior are important factors influencing larval dispersal. Competent abalone larvae attach to the substratum by their foot, and metamorphose into crawling postlarvae after contact with an appropriate chemical cue (Kawamura et al. 2005). In the natural environment, abalone larvae settle primarily on crustose coralline algae (CCA), and remain there at least for a few months (Kawamura et al. 1998, Roberts 2001). In experimental conditions, larval metamorphosis can be delayed if they do not contact an appropriate stimulus, but an excessive prolongation of the larval period results in lower growth and survival rates (Roberts \& Lapworth 2001, Takami et al. 2002). For newly metamorphosed postlarvae of Haliotis discus hannai, the periods after fertilization have been reported to be $<1 \mathrm{wk}$ (Takami et al. 2006). Short larval periods and early settlement may be less risky and common in the natural environment. Therefore, this study focused on the dispersal of larvae for $1 \mathrm{wk}$ after spawning. Influence of larval behavior on dispersal is still unclear for abalone species. A laboratory study of $H$. madaka larvae showed phototaxis and upward swimming behavior during the trochophore stage, and aggregation near the surface during both trochophore and veliger stages (Yano \& Ogawa 1977). In contrast, larvae of the 3 study species are unevenly distributed throughout the water column and do not show fixed tendencies (e.g. aggregation at the deepest layer) in our study area (Horii et al. 2006). As we attempted to simulate larval dispersal in the field, passive and neutrally buoyant particles were employed. We focused on the dispersal of larvae in the water column since passive particles can not simulate the individuals that stay near the bottom, or in the rock crevices. The individuals in the water column are likely to disperse more widely compared to the ones in the slower flow environments (e.g. near the bottom). Therefore, the larval dispersal in this study should be interpreted as the maximum dispersal.

There are no studies simulating larval dispersal of abalone validated with the distribution of larvae in the field. The problem lies in the difficulty of sampling larvae in their natural environment (Tomita et al. 1977, Breen \& Adkins 1980, McShane et al. 1988). In the present study, larvae were successfully caught for determining their density and distribution. Larvae of Haliotis discus discus, $H$. gigantea and $H$. madaka can be distinguished by using molecular and monoclonal antibody techniques (Hamaguchi et al. 2006). However, we did not identify each species in this study and considered these species as a whole, since our main interest was not on their species-specific differences. The smaller species Haliotis diversicolor - also found in the study area — can be distinguished from the larger species by its smaller larval shell size (see 'Materials and methods: Larval surveys').

From the ongoing low catch of large abalone in the study area, it is unclear whether the populations in the refugium are contributing to the regeneration of the natural population. Thus, the aims of the present study were to (1) clarify the larval dispersal processes and settlement sites, and (2) evaluate the existing harvest refugium and estimate the suitability of other areas for larval sources for the 3 large abalone species in the study areaHaliotis discus discus, H. gigantea, and H. madaka.

\section{MATERIALS AND METHODS}

Larval surveys. The study site (Nagai, Kanagawa Prefecture, Japan) is located on the east side of Sagami

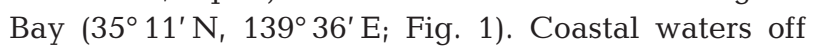




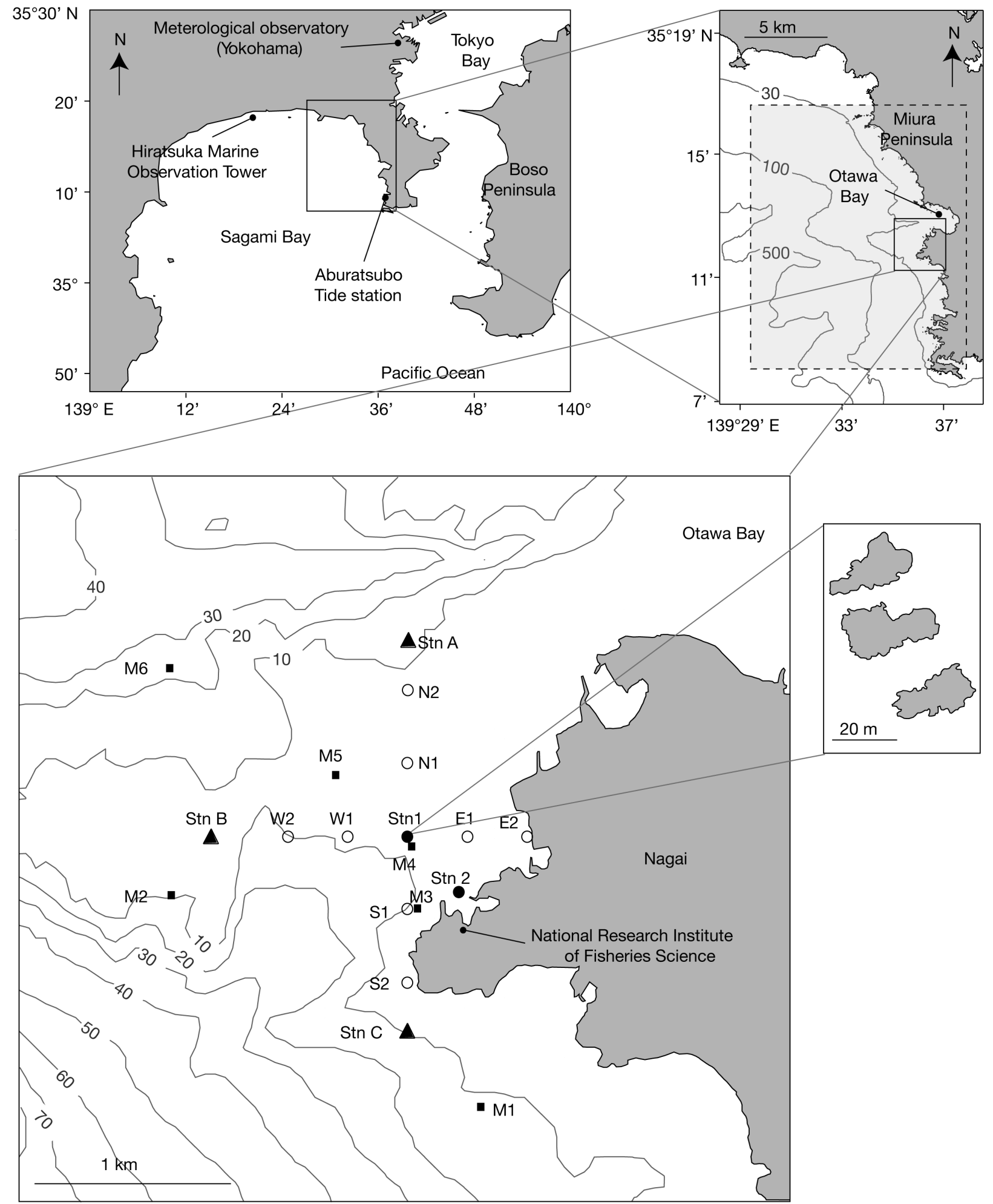

Fig. 1. Site map showing locations of regular abalone larval sampling stations (@), additional sampling stations at larval peaks $(\mathrm{O})$, current meters $(\boldsymbol{\square})$, hypothetical reproductive sources $(\boldsymbol{\Delta})$, the metrological observatory in Yokohama, the Hiratsuka Marine Observation Tower, and the tide station in Aburatsubo. Isobaths are in meters. The main refugium is located at Stn 1, and the outlines of abalone reefs in this refugium are shown in the lower right map. The upper right map shows the model domain L1, and the shaded area inside the box marked with a dashed line is the nested domain/particle-tracking domain (L2) 
Nagai are one of the best fishing grounds for abalone in Kanagawa Prefecture. It was selected as a study site because of its abundance of abalone. The refugium (Stn 1), which consists of artificial reefs, is approximately $400 \mathrm{~m}$ from the shore.

Abalone larvae were sampled approximately 3 times a week at the refugium (Stn 1) and the site near the National Research Institute of Fisheries Science at Nagai (Stn 2) from November to December, 2005, which is the peak of the spawning season for the 3 large abalone species in this region (Fig. 1). Larvae were captured with a CMS Type II plankton net with a mouth diameter of $36 \mathrm{~cm}$ and a mesh size of $100 \mu \mathrm{m}$. The net was towed horizontally at 3 different depths (Stn 1: 0 m, 3 m, $6 \mathrm{~m}$; Stn 2: $0 \mathrm{~m}, 1.5 \mathrm{~m}, 3 \mathrm{~m}$ ) in a continuous manner (step tow), and it was conducted 3 times at each station. The volume of water filtered by the net was calculated using the number of revolutions obtained with a flow meter. The net was towed for 45 to $60 \mathrm{~s}$ at each depth level at a speed of $1.5 \mathrm{kn}$. When the number of larvae at Stn 1 and/or Stn 2 was relatively high, a total of 8 sampling stations at $370 \mathrm{~m}$ and $740 \mathrm{~m}$ north (N1, N2) and south $(\mathrm{S} 1, \mathrm{~S} 2)$, and $300 \mathrm{~m}$ and $600 \mathrm{~m}$ east (E1, E2) and west (W1, W2) of Stn 1 were added (Fig. 1). The larval density peaks observed are hereafter referred to as P1 (November 14, 2005), P2 (November 28), P3 (December 8), and P4 (December 21). The samplings at 8 additional stations were conducted at P1, P2, and P3. This largescale larval survey at P4 was not implemented due to rough oceanic conditions. The samples were sorted after the addition of a $99 \%$ ethanol solution and examined under a dissection microscope. We counted the number of abalone larvae to determine their distribution, checked the development of eyespots to estimate the time of fertilization, and observed and measured shell morphology and length to distinguish the larvae of the 3 target abalone species from other similar organisms, including Haliotis diversicolor; the latter also inhabits the study area but has smaller larvae $(257 \mu \mathrm{m}$ along the long axis; Hayashi 1983) and an earlier spawning season than the study species (Onitsuka et al. 2007). Based on the sizes of the 3 large abalone species reported by Hayashi (1983), larvae $\leq 270 \mu \mathrm{m}$ along the long axis were excluded from the count. The daily mean larval densities at Stns 1 and 2 were compared using Spearman's correlation coefficient.

Environmental factors. The atmospheric pressure at sea level, wave height, tidal height, lunar condition and bottom seawater temperature were monitored during the study period to make an assumption on the spawning cues of the target species. The atmospheric pressure at sea level was obtained from the Japan Meteorological Agency in Yokohama (Fig. 1). The wave height grade and bottom seawater temperature (the latter monitored at Stn 1) was provided by the
National Research Institute of Fisheries Science at Nagai. The one-tenth significant wave height at Hiratsuka Marine Observation Tower was provided by the Hiratsuka experimental station of the National Research Institute for Earth Science and Disaster Prevention. Excluding weekends and holidays, the wave height grade was classified daily into 5 grades - 0 : calm sea; 1 : little ground swell; 2 : ground swell; 3 : a few white-crested waves with a south wind; 4: many white-crested waves with a strong south wind (Onitsuka et al. 2007). The tidal height was measured at Aburatsubo tidal station, of the Geographical Survey Institute (Fig. 1). The lunar condition was provided by the National Astronomical Observatory of Japan.

Estimation of time of fertilization. The time of fertilization was estimated from the water temperature and presence of eyespots. The time between fertilization and eyespot development of the captured larvae was calculated using an equation for Haliotis discus discus modified from Seki \& Kan-no (1977):

$$
t=\frac{10^{2}}{0.1826 T-1.52}
$$

where $t$ is the time between fertilization and eyespot development, and $T$ is the average of the water column temperature ( 6 to $7 \mathrm{~m}$ ) and bottom seawater temperature $(8 \mathrm{~m})$. Where data for water column temperature were missing, due to the replacement of the current meter (see 'Hydrodynamic model' below), only the bottom seawater temperature was used for the calculation. The fertilization time of the captured larvae was calculated by subtracting $t$ from the time of the sampling, in which the first larva of the day was captured. The time of fertilization was used to estimate the time of spawning.

Hydrodynamic model. In the study area, 6 current meters (M1 to M6) were moored to record the current velocity and water column temperature at inshore and offshore sites (Fig. 1). These measurements were taken between October 12, 2005 and March 1, 2006. Current meters M1 and M6 were moored to ropes connecting buoys for stationary nets. Current velocity was monitored at 6 and $9 \mathrm{~m}$ (referred to as upper and lower, respectively) below the surface. The measurements by M2, M3, M4 and M5 were made only between 6 and $7 \mathrm{~m}$. The M1 mooring rope broke, and M4 was lost. These current meters were replaced, but the current data obtained from them were not used.

The model location was on the west coast of Miura Peninsula (Fig. 1). This model solves the free surface, hydrostatic, and primitive equations. For the vertical coordinate system, the $z$-coordinate was employed with multiple layers that allowed water transport across layers. The model assumes that the fluid is incompressible and density is constant. The shear 
stress on the ocean surface (in the model domain L2), $\tau_{\mathrm{s}}$, that nudges the model solution toward the current observations was parameterized as:

$$
\tau_{\mathrm{s}}=\rho C_{\mathrm{D}}\left(U_{\mathrm{o}}-U\right)\left|U_{\mathrm{o}}-U\right|
$$

where $\rho$ is the density of water, and $C_{\mathrm{D}}$ is a drag coefficient, which can be considered as a nudging parameter (Lewis et al. 1998). $U_{\mathrm{o}}$ is the observed current velocities at the current meters, and $U$ is the model current velocity at the surface layer. This approach allowed the observed current data to act as if there were an additional layer of water overlying the surface (Lewis et al. 1998). The differences between observed current velocity and model predicted velocity, $\left(U_{\mathrm{o}}-U\right)\left|U_{\mathrm{o}}-U\right|$, at 4 current measurement sites (M2, M3, M5 and upper M6) were averaged and used in Eq (2).

The bathymetries of model domain L1 consisted of a coarse $200 \times 200 \mathrm{~m}$ regular grid, and the nested domain L2 consisted of a fine $50 \times 50 \mathrm{~m}$ regular grid. These grids were created from the bathymetry data of Marine Explorer (Environmental Simulation Laboratory, Saitama) based on the nautical charts issued by the Japan Coast Guard. The minimum depth was set at $4 \mathrm{~m}$. The model domain L1 extended $16 \mathrm{~km}$ longitudinally and $23.8 \mathrm{~km}$ latitudinally. The harmonic constants of $\mathrm{O}_{1}, \mathrm{~K}_{1}, \mathrm{M}_{2}$, and $\mathrm{S}_{2}$ at the 4 boundary corners of L1, obtained by harmonic analysis of tidal data calculated with the NAO.99Jb model (Matsumoto et al. 2000), were used as boundary conditions. The model domain L2 extended $13.1 \mathrm{~km}$ longitudinally and $16.1 \mathrm{~km}$ latitudinally. The model results of the domain L1 were used as boundary conditions of this model domain. Both domains consist of 3 vertical layers. The first, second and third layers were 0-10, 10-20 and 20-50 m deep, respectively. The first layer was set to $10 \mathrm{~m}$ depth, since the observation depth of the current, which was assimilated in the model, was 6 to $7 \mathrm{~m}$ deep. The seawater (ca. $50 \mathrm{~m}$ deep) in this region during the modeled period is usually well mixed (e.g. Kasai et al. 2000, Hashimoto et al. 2005). Details of the hydrodynamic model are shown in Table 1.

Model results were compared with current meter data at M2, M3, M5, and upper M6 in the period corresponding to the particle-tracking experiments to estimate a suitable drag coefficient. The magnitude $R$ of the complex correlation coefficient and the angular displacement between the observed and model currents were calculated as follows (Kundu 1976, Shulman et al. 2002):

$$
\begin{gathered}
R=\sqrt{\operatorname{Re}^{2}+\operatorname{Im}^{2}} \\
\operatorname{Re}=\frac{\Sigma_{t}\left(u_{t}^{\mathrm{o}} u_{t}^{\mathrm{m}}+v_{t}^{\mathrm{o}} v_{t}^{\mathrm{m}}\right)}{\sqrt{\Sigma_{t}\left[\left(u_{t}^{\mathrm{o}}\right)^{2}+\left(v_{t}^{\mathrm{o}}\right)^{2}\right] \Sigma_{t}\left[\left(u_{t}^{\mathrm{m}}\right)^{2}+\left(v_{t}^{\mathrm{m}}\right)^{2}\right]}}
\end{gathered}
$$

$$
\begin{gathered}
\operatorname{Im}=\frac{\Sigma_{t}\left(u_{t}^{\mathrm{o}} v_{t}^{\mathrm{m}}-v_{t}^{\mathrm{o}} u_{t}^{\mathrm{m}}\right)}{\sqrt{\Sigma_{t}\left[\left(u_{t}^{\mathrm{o}}\right)^{2}+\left(v_{t}^{\mathrm{o}}\right)^{2}\right] \Sigma_{t}\left[\left(u_{t}^{\mathrm{m}}\right)^{2}+\left(v_{t}^{\mathrm{m}}\right)^{2}\right]}} \\
\theta=\tan ^{-1} \frac{\Sigma_{t}\left(u_{t}^{\mathrm{o}} v_{t}^{\mathrm{m}}-v_{t}^{\mathrm{o}} u_{t}^{\mathrm{m}}\right)}{\Sigma_{t}\left(u_{t}^{\mathrm{o}} u_{t}^{\mathrm{m}}+v_{t}^{\mathrm{o}} v_{t}^{\mathrm{m}}\right)}
\end{gathered}
$$

where $u_{t}^{\mathrm{o}} v_{t}^{\mathrm{o}}$ and $u_{t}^{\mathrm{m}}, v_{t}^{\mathrm{m}}$ are observed and model eastward and northward components of current velocity at time $t_{i} \theta$ is the average counterclockwise angle of the model current with respect to the observed current.

Particle-tracking model. The particle-tracking model simulated larval dispersal by using neutrally buoyant and passive particles; it did not include larval swimming behavior and mortality. The transport of abalone larvae was simulated using the current velocities calculated with the hydrodynamic model and a 3dimensional advection-diffusion scheme (Kim et al. 2007). The positions of passive particles $X p(t+\delta t)$ at a time step $t+\delta t$ were calculated as:

$$
X p(t+\delta t)=[X p(t)+U(t) \times \delta t]+\delta l_{\text {diff }}
$$

where $X p(t)$ is the position of the particle at the previous time step $t$. The particles were advected with current velocity $U(t)$, which were weighted by the distances from 4 adjacent grid points with current velocities calculated by the hydrodynamic model. $\delta l_{\text {diff }}$ is a diffusion scheme, and the horizontal eddy viscosity of the domain L2 in the hydrodynamic model was used for the horizontal diffusivity of the particles.

Since the fertilized eggs of abalone sink (Najmudeen \& Victor 2004), the dispersal of larvae is unlikely to occur before the trochophore hatch (Prince et al. 1987). The particles were therefore released at the estimated time of hatch. The 10000 particles were released at the refugium (Stn 1) evenly and horizontally $0.1 \mathrm{~m}$ from the

Table 1. Main parameters used in simulations, with their values or delimitations

\begin{tabular}{|lc|}
\hline Parameter & Value/delimitation \\
\hline Coriolis parameter $\left(35^{\circ} 10^{\prime} \mathrm{N}\right)$ & $8.38 \times 10^{-5}$ \\
Horizontal eddy viscosity (L1) & $10.0 \mathrm{~m}^{2} \mathrm{~s}^{-1}$ \\
Horizontal eddy viscosity (L2) & $1.0 \mathrm{~m}^{2} \mathrm{~s}^{-1}$ \\
Interfacial friction coefficient & 0.001 \\
Bottom friction coefficient & 0.0026 \\
Time step & $1.5 \mathrm{~s}$ \\
Number of grid cells in L1 & $80 \times 119$ \\
( $x$ and $y$ directions) & $262 \times 322$ \\
Number of grid cells in L2 & 3 \\
( $x$ and $y$ directions) & Number of layers (L1 and L2) \\
Period of assimilation & Oct 13, 2005-Dec 16, 2005 \\
Current meter data assimilated & M2, M3, M5, upper M6 \\
\hline
\end{tabular}


bottom. The length of time between fertilization and hatch, $t$, was calculated using an equation for Haliotis discus discus modified from Seki \& Kan-no (1977):

$$
t=\frac{10^{2}}{0.644 T-5.55}
$$

where $T$ is the average of the water column temperature $\left({ }^{\circ} \mathrm{C}\right)$ and bottom seawater temperature, detailed above. The time of hatch was calculated by adding $t$ to the estimated time of fertilization. The estimated time of fertilization gives the latest time of fertilization for individuals with eyespots. It is likely that eggs of these larvae were fertilized at the estimated time when captured larvae consisted of individuals both with and without eyespots. When the eyespots were present in all larvae, the timing of potential spawning cues (mentioned in 'Results') was assumed as the estimated time of spawning since the spawning could have taken place before the estimated time of fertilization. In this case, the estimated time of spawning was used for calculating the time of hatch, instead of estimated time of fertilization. The time required for metamorphosis of $H$. discus hannai larvae in the water below $20^{\circ} \mathrm{C}$ is $85.5 \mathrm{~h}$ (Seki \& Kan-no 1981), although it can be longer if they do not come into contact with an appropriate stimulus (Takami et al. 2002). Newly metamorphosed larvae of $H$. discus hannai in the field have been determined to be 4 to $6 \mathrm{~d}$ old (Takami et al. 2006). Since the larval period in a natural environment is unknown for the 3 species in the present study, we assumed that the larvae undergo benthic life stages within 3 to $7 \mathrm{~d}$ of spawning. The number of particles transported into each grid cell was added hourly, and this accumulation was calculated to elucidate possible settlement locations.

Among the 3 Haliotis species in the present study, $H$. madaka inhabits the deepest range, i.e. between 25 and $31 \mathrm{~m}$ (Ino 1952). Depth preference is apparently fixed in the late veliger stage in $H$. discus hannai (Sasaki \& Shepherd 1995). It is therefore assumed that larvae of the target species settle in areas up to $30 \mathrm{~m}$ deep. To estimate the transport success, the proportion of particles in these areas was calculated against the total number of released particles. Particles that were transported onto land were reflected back to the position at the previous time step, and particles transported outside the domain L2, including the outermost grid cells, were eliminated. In addition, the particles were released at hypothetical reproductive sources (Stns A, $\mathrm{B}$ and $\mathrm{C}$ ) - which were located $1 \mathrm{~km}$ north, west, and south of the refugium (Stn 1) - so that Stn 1 could be compared to the hypothetical reproductive sources to evaluate its suitability and to identify more effective locations for reproductive sources (Fig. 1).

Results from the particle-tracking model were validated with field sampling data of larvae. The observed and modeled results were normalized by dividing the concentration of larvae or number of particles at each station with that at Stn 1, so that these ratios could be represented at the same order of magnitude. The ratios between the larval densities at Stn 1 and Stn 2 were compared with the particle-tracking results (i.e. ratios between numbers of particles at these stations) obtained in accordance with the sampling time. In addition, the ratios at all sampling stations were compared between observation and model results using Spearman's correlation coefficient.

\section{RESULTS}

\section{Larval distribution}

The first occurrence of larvae was observed on November 9, 2005, and larval density peaks (P1 to P4) were observed on 4 occasions during the survey period (Fig. 2). The highest densities at Stn 1 and Stn 2 were approximately 2.24 and 2.00 ind $\mathrm{m}^{-3}$, respectively. The larval densities showed a high correlation (Spearman's correlation coefficient, $r_{S}=0.81, p<0.01$, Fig. 2a) between Stns 1 and 2 .

At P1, the larval density at Stn 1 decreased to $29.8 \%$ between the first sampling $(09: 39 \mathrm{~h})$ and the second sampling (17:23 h), possibly due to dispersal of larvae (Fig. 3). The density at Stn 2 was the second highest at P1 and the highest at P2 among sampling stations. The larval densities were slightly higher at northern sampling stations, N1 and N2, at P3.

\section{Potential cues and time of spawning}

Increases in wave height and decreases in the atmospheric pressure at sea level were detected within 1 to $4 \mathrm{~d}$ of the peaks in larval density (Fig. 2). The presence of eyespots on larvae was used as an indicator of the developmental stage. At these peaks, eyespots had formed in most individuals except at P2 (Table 2). At P1, 84.1\% of larvae had developed eyespots, and the time of fertilization was estimated to be about $48 \mathrm{~h}$ before sampling using Eq. (1). This estimated time of fertilization was consistent with the above-mentioned environmental changes. The time of fertilization was estimated at approximately $56 \mathrm{~h}$ before sampling at P3 and $71 \mathrm{~h}$ before sampling at P4. However, the fertilization likely took place before the estimated times because the eyespots were present on all individuals in both samplings. The changes in wave height and atmospheric pressure were observed $1 \mathrm{~d}$ before the estimated time of fertilization of larvae captured at P3 and at P4. Eyespots were present in 
$34.8 \%$ of the larvae captured at P2, indicating the mixture of individuals with and without eyespots, and the time of fertilization was estimated to be about $46 \mathrm{~h}$ before sampling. Since the changes in the environmental factors were observed after the estimated time

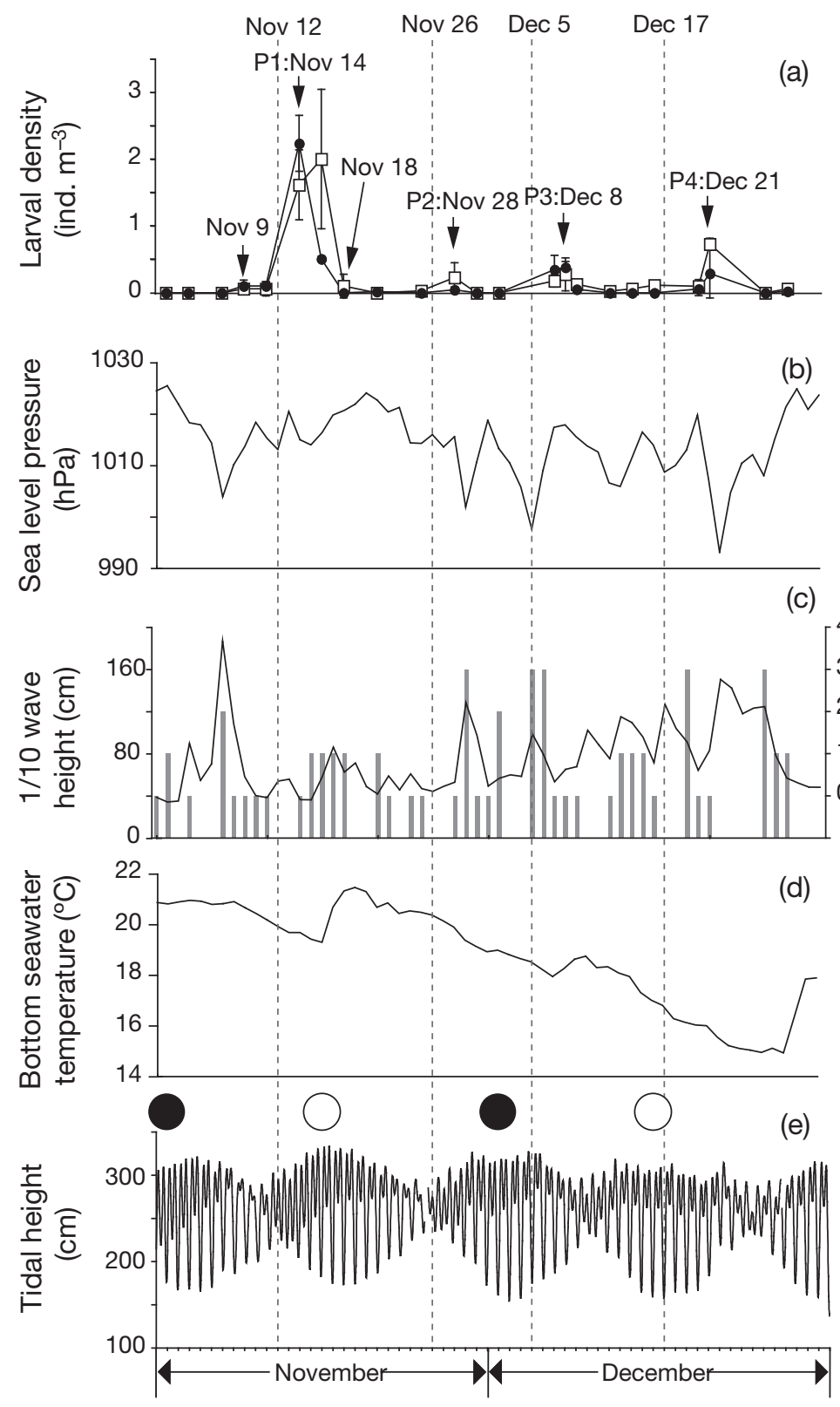

Fig. 2. Haliotis discus discus, $H$. gigantea and $H$. madaka. Time series of abalone larval density and environmental factors from November to De-

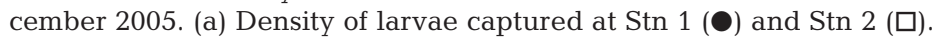
(b) Atmospheric pressure at sea level in Yokohama. (c) 1/10 wave height at Hiratsuka (solid line) and wave height class at Nagai (gray bars; see 'Materials and methods: Environmental factors' for wave height classification). (d) Water temperature at the seabed of Stn 1. (e) Tidal height at Aburatsubo and lunar phase. The moon phases are indicated by (new) and $O$ (full). Vertical dashed lines: estimated date of spawning; error bars: SD; P: peak of fertilization for these larvae, these factors may not be related to the spawning of the P2 larvae. The dates of spawning were estimated to be November 12 and 26 and December 5 and 17 for the larval density peaks (Fig. 2).

The range in temperature on the seabed of Stn 1 in November and December was 14.9 to $21.5^{\circ} \mathrm{C}$ (Fig. 2). Steep changes in the water temperature were not observed before most of the larval appearances. The daily average temperature at the bottom of Stn 1 rose by approximately $1.4^{\circ} \mathrm{C}$ on November 17 , and larvae were captured on the next day. However, eyespots were present in all larvae, and it was estimated that they were fertilized approximately $45 \mathrm{~h}$ before sampling. Therefore, it seems that the change in the water temperature was not related to the occurrence of these larvae. No relationship between the occurrence of larvae and the change in tidal height or lunar phases was observed in this study.

\section{Drag coefficient estimation for the hydrodynamic model}

Hydrodynamic model results were compared among different drag coefficients (Table 3). By assimilating the observed current data into the model with higher $C_{\mathrm{D}}$, the model showed a higher correlation and smaller angle between the observed and model currents. This indicates an improvement in the predictive ability of the model. Assimilation with $C_{\mathrm{D}}$ of 0.3 or higher improved values of $R$ and $\theta$. When $C_{\mathrm{D}}$ was $1.1 \times 10^{-2}$, the mean of the absolute $\theta$ value at all current meter stations, which provided data that was subsequently assimilated into the model, was the lowest after $C_{\mathrm{D}}=1.3 \times$ $10^{-2}$ and $1.5 \times 10^{-2}$, and the mean $R$ value was the highest. Thus, the model results calculated using $C_{\mathrm{D}}=1.1 \times 10^{-2}$ were employed in the larval dispersal simulations.

\section{Particle-tracking model validation}

The particles were released based on the estimated time of hatch (Table 4). The larval densities in the field and numbers of particles in the particle-tracking model were compared at sampling stations (Fig. 4). The Spearman's correlation coefficients at P1, P2, and P3 were $r_{S}=0.07,0.03$, and 0.14 , respectively. 

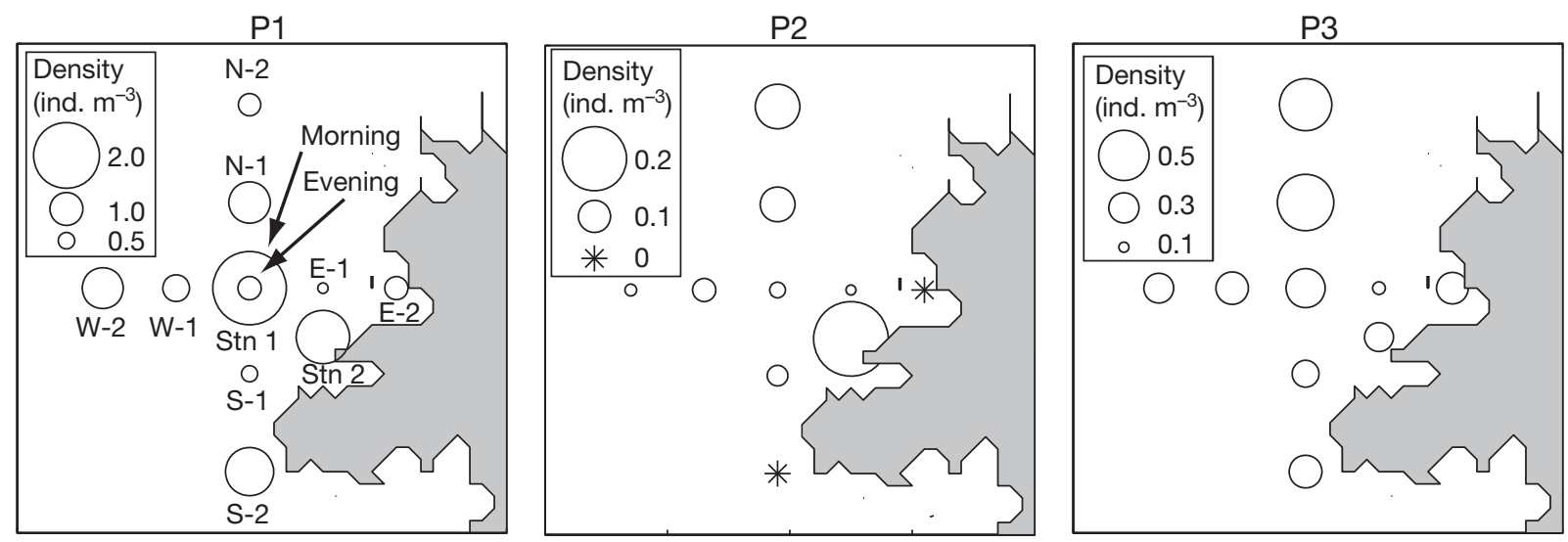

Fig. 3. Haliotis discus discus, H. gigantea and H. madaka. Density and distribution of abalone larvae around the refugium (Stn 1). Panels show larval density and distribution at density peaks on November 14 (P1, left), November 28 (P2, middle), and December 8 (P3, right), 2005. The larger circle shown at Stn 1 at P1 indicates the density in the morning, and the smaller one indicates the density in the evening

Table 2. Haliotis discus discus, H. gigantea and H. madaka. Percentage of abalone larvae with eyespots and estimated time between fertilization and development of eyespots

\begin{tabular}{|lcrrrc|}
\hline $\begin{array}{l}\text { Peaks in } \\
\text { larval } \\
\text { density }\end{array}$ & $\begin{array}{c}\text { Peak } \\
\text { date } \\
(\mathrm{d} / \mathrm{mo} / \mathrm{yr})\end{array}$ & $\begin{array}{c}\text { Larvae } \\
(\mathrm{n})\end{array}$ & \multicolumn{2}{c}{$\begin{array}{c}\text { Larvae } \\
\text { with } \\
\text { eyespots } \\
(\mathrm{n})\end{array}$} & $\begin{array}{c}\text { Tertilization and eyespot } \\
\text { development }(\mathrm{h})\end{array}$ \\
\hline 1 & & & & & \\
2 & $14 / 11 / 05$ & 409 & 343 & 84.1 & 47.8 \\
3 & $28 / 11 / 05$ & 23 & 8 & 34.8 & 46.3 \\
4 & $08 / 12 / 05$ & 96 & 96 & 100 & 56.0 \\
\hline
\end{tabular}

These coefficients were not significant. Since the observed larval densities were highly correlated between Stns 1 and 2 (Fig. 2), model validation was performed based on the ratios between Stns 1 and 2 (Fig. 4). The ratios between Stns 1 and 2 in the field (larval density) and model (number of particles) were, respectively, 1:0.73 and $1: 0.56$ at $\mathrm{P} 1,1: 4.77$ and $1: 1.50$ at $\mathrm{P} 2$, and $1: 0.74$ and 1:0.67 at P3. The model results at P1 and P3 were consistent with the field observation.

The second sampling at Stn 1 in the P1 simulation showed a decrease in the number of particles, which is also consistent with the field observation. The relative concentration of larvae in the field at P2 was 4.77 times higher at Stn 2 than Stn 1 while the ratio in the model was 1.5 times higher at Stn 2. Based on the ratios between Stns 1 and 2 from the field data and model results, it was considered to be a discrepancy. For this reason, only dispersal of larvae caught at P1 and P3 were simulated.

\section{Regional hydrodynamics}

The $25 \mathrm{~h}$ running mean currents at M2, M3, M5, and M6 from October 14, 2005 are shown in Fig. 5. The low- passed currents were mostly slower than $0.10 \mathrm{~m} \mathrm{~s}^{-1}$, and the predominant currents ran parallel to the coast. The data of the upper (6 $\mathrm{m}$ ) and lower (9 $\mathrm{m}$ ) layers at M6 show similarities in speed and direction, indicating that these 2 layers were governed by the same current. Northward components of currents were predominant at M2 and M5. In contrast, southward components were predominant at M3 and M6. These results indicate the clockwise and counterclockwise flows inshore and offshore, respectively.

\section{Larval dispersal processes}

The larval dispersal processes differed significantly between the simulations of P1 and P3 (Figs. $6 \&$ 7). In

Table 3. The magnitude of the complex correlation coefficient $(R)$ and the angular displacement between the observed and simulated currents $(\theta)$. The values were calculated for the period of larval dispersal simulations (23:00 h November 12, 2005 to $01: 00 \mathrm{~h}$ December 14,2005 ) and averaged among 4 current measurement sites. $C_{\mathrm{D}}$ : drag coefficient

\begin{tabular}{|lcc|}
\hline$C_{\mathrm{D}}\left(\times 10^{-2}\right)$ & $R$ & $\theta$ \\
\hline No assimilation & 0.309 & 26.6 \\
0.1 & 0.297 & 16.0 \\
0.3 & 0.336 & 20.6 \\
0.5 & 0.469 & 12.4 \\
0.7 & 0.532 & 12.7 \\
0.9 & 0.561 & 12.7 \\
1.1 & 0.577 & 12.2 \\
1.3 & 0.573 & 11.3 \\
1.5 & 0.563 & 10.8 \\
\hline
\end{tabular}


Table 4. Timings of particle release in the larval dispersal simulations

\begin{tabular}{|c|c|c|c|c|c|}
\hline $\begin{array}{l}\text { Peak in } \\
\text { larval } \\
\text { density }\end{array}$ & $\begin{array}{c}\text { Peak } \\
\text { date }\end{array}$ & $\begin{array}{c}\text { Calculated } \\
\text { time between } \\
\text { fertilization and } \\
\text { eyespot } \\
\text { development (h) }\end{array}$ & $\begin{array}{l}\text { Estimated time } \\
\text { and date of } \\
\text { fertilization } \\
\text { or spawning } \\
\text { (h:min) }\end{array}$ & $\begin{array}{l}\text { Calculated } \\
\text { time between } \\
\text { fertilization } \\
\text { and hatch } \\
\text { (h) }\end{array}$ & $\begin{array}{l}\text { Estimated time } \\
\text { and date of } \\
\text { hatch (particle } \\
\text { release) } \\
\text { (h:min) }\end{array}$ \\
\hline 1 & 14/11/05 & 48 & $09: 00,12 / 11 / 05$ & 14 & $23: 00,12 / 11 / 05$ \\
\hline 2 & $28 / 11 / 05$ & 46 & $11: 00,26 / 11 / 05$ & 13 & $00: 00,27 / 11 / 05$ \\
\hline 3 & 08/12/05 & 56 & $09: 00,05 / 12 / 05^{\mathrm{a}}$ & 16 & $01: 00,06 / 12 / 05$ \\
\hline
\end{tabular}

the simulation of P1 larvae, the particles released at Stn 1 moved southwestward for up to $4 \mathrm{~d}$ after the release (Fig. 6), being advected by strong southwestward currents. They were then transported toward the shore and consequently moved northwestward along the coast. Even when the particles were released at hypothetical reproductive sources, the
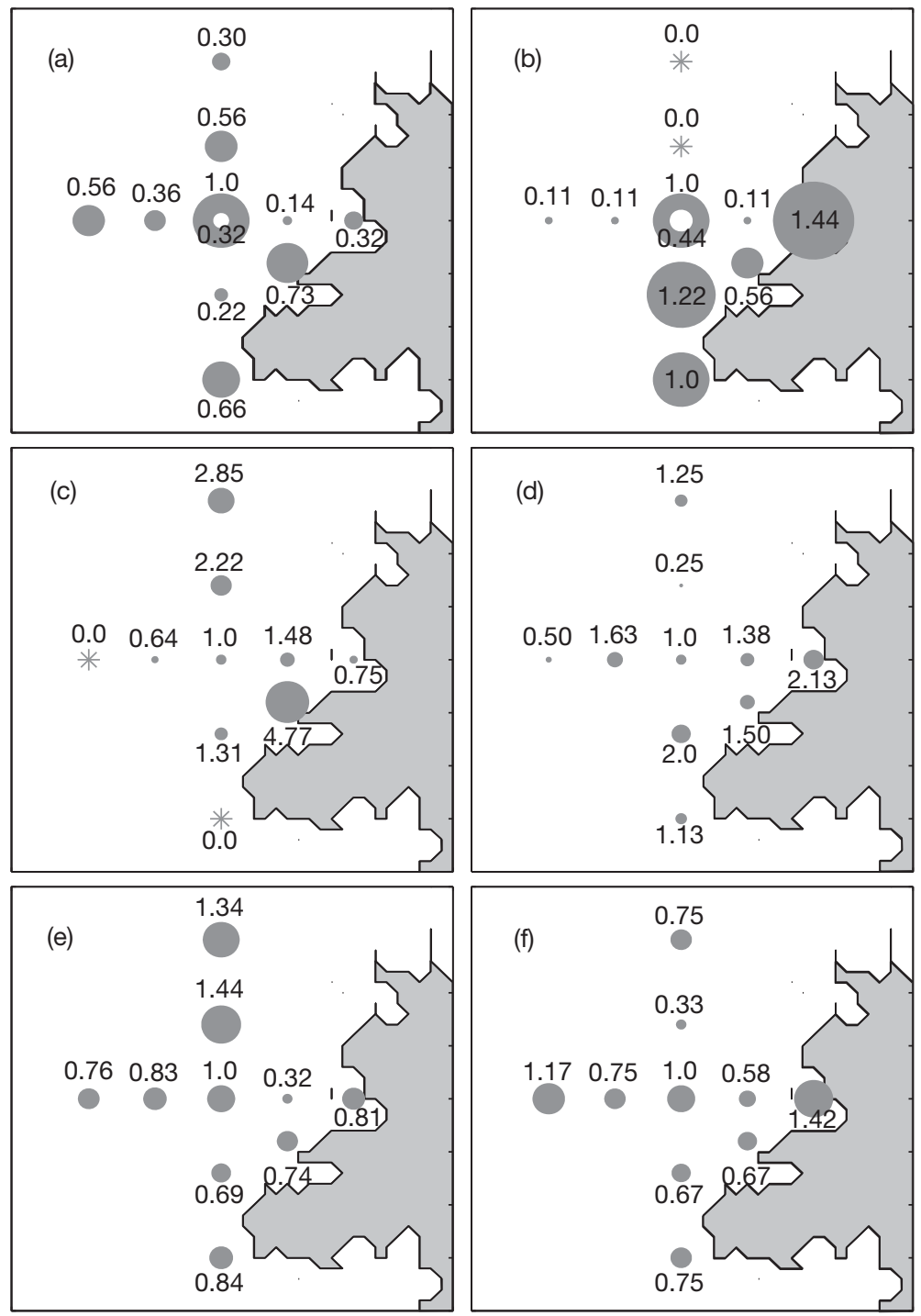

Fig. 4. Haliotis discus discus, H. gigantea and H. madaka. Comparisons of $(a, c, e)$ observed and $(b, d, f)$ simulated distributions of abalone larvae. Numbers indicate the relative densities of larvae $(\mathrm{a}, \mathrm{c}, \mathrm{e})$ and the relative numbers of particles $(\mathrm{b}, \mathrm{d}, \mathrm{f})$. Distributions on $(\mathrm{a}, \mathrm{b})$ November 14 (P1), $(\mathrm{c}, \mathrm{d})$ November 28 (P2), and (e,f) December 8 (P3) are shown. The white circles at Stn 1 in (a) and (b) indicate the relative larval density and relative number of particles in the evening, respectively. (*) 0.0 value dispersal processes were similar. The particles in the P3 simulation were gradually dispersed offshore from the release sites through the simulated period (Fig. 7). Although the particles released at Stn B dispersed slightly northward while moving offshore, the dispersal processes from all release sites were similar. The model results indicate that the dispersal processes of larvae differed in these 2 periods due to the difference in the hydrodynamic conditions.

\section{Suitable location for larval source}

Compared to the P1 simulation, the results indicate a higher proportion of particles inside the shallow areas $(\leq 30 \mathrm{~m})$ in the P3 simulation throughout the simulated period, except when the particles were released from Stn B (Fig. 8). The difference in transport success between these 2 periods appears to be due to the greater dispersal in the P1 simulation (Fig. 6). The percentage was highest on Day 3 when released from Stn 1 in the P1 simulation, and it gradually declined throughout the settlement period. The increase and gradual decrease of the transport success on Days 5 and 6 in the P1 simulation are apparently due to the transport of particles toward the shore. Particles from Stn 1 showed the highest and second highest proportions in the shallow areas $(\leq 30 \mathrm{~m})$ in the $\mathrm{P} 1$ and $\mathrm{P} 3$ simulations, respectively. Although Stn A showed the highest transport success in the P3 simulation, the difference in transport success between Stn A and Stn 1 was not as high as that in the P1 simulation. These results indicate that Stn 1 is the most suitable location for a reproductive source. 
$\mathrm{M} 2$
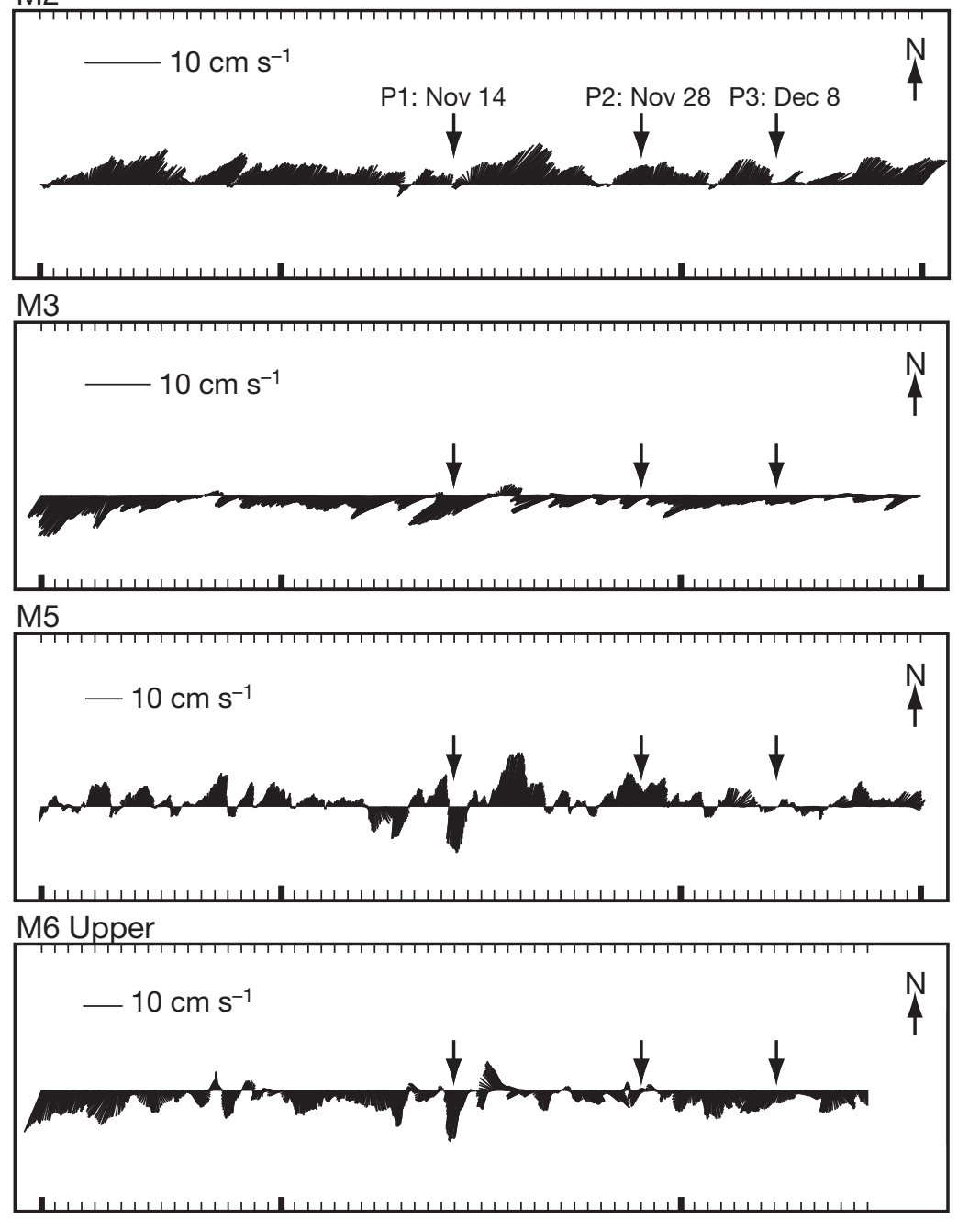

M6 Lower

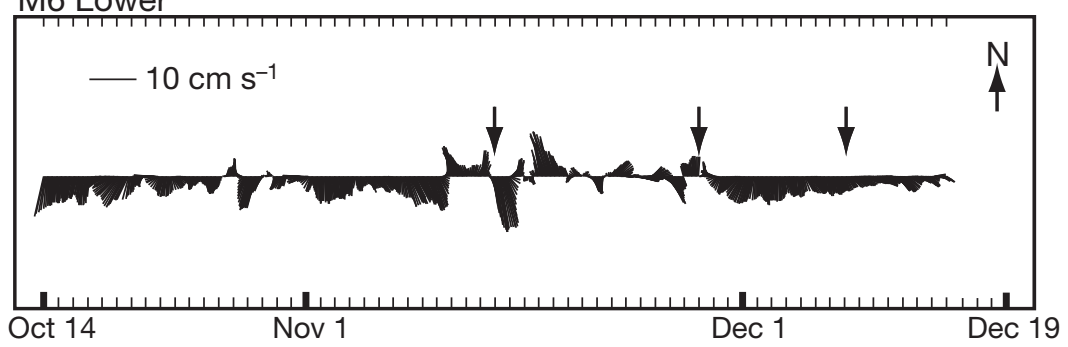

Fig. 5. Fluctuations of low-passed (25 h running mean) currents at M2, M3, M5, and M6 (upper and lower). Arrows indicate the larval density peaks

Particles from Stn 1 and Stn C accumulated in the southern coastal area in the same simulation. In the P3 simulations, particles from Stn A and Stn C also accumulated from Otawa Bay westward. The area southwest of Stn 1 showed high accumulations when particles were released from Stns 1, A, and C. In comparison with the P1 simulation, the areas with high accumulation of particles tended to be near the particle release sites in the P3 simulation.

\section{DISCUSSION}

The hydrodynamic model showed an improvement by the assimilation of the observed current data. The results of larval dispersal simulations indicate that larval dispersal processes and settlement sites of abalone larvae in Sagami Bay were influenced by local hydrodynamics, varying through the spawning season. The distinct larval dispersal patterns in 2 simulated periods (P1 and P2 simulations) were (1) transport toward the coast after dispersal offshore and (2) gradual dispersal offshore. At the end of the simulations for larval dispersal from the refugium (Stn 1), the mean distance of particles (exclusive of particles outside the domain) from the release site (Stn 1) was $3 \mathrm{~km}$ greater in the P1 simulation $(5.9 \mathrm{~km})$ than the P3 simulation $(2.9 \mathrm{~km})$. In the P1 simulations for larval dispersal from all particle release sites (Stns 1, A, B and C), the northward (shoreward) transport of particles after being dispersed offshore in a southwest direction was apparently due to the intrusion of warm water into Sagami Bay, induced by an approach of the Kuroshio path. Warm water intrusions could occur during the peak of the spawning season. For example, blue

\section{Potential settlement areas}

The sites where particles accumulate indicate the larval transport into these areas. When particles were released from Stn 1, the area from Otawa Bay westward showed high accumulations in both P1 and P3 simulations (Figs. $9 \& 10$ ). High accumulations were observed along the $30 \mathrm{~m}$ isobath in the P1 simulation. crab larvae can be transported onshore by physical mechanisms, such as wind (Epifanio 1995) and relaxing upwelling fronts (Shanks et al. 2000) with their vertical movement. In the case of local large abalone species, onshore larval transport may be linked to current-related phenomena, such as Kyucho (stormy current; e.g. Matsuyama et al. 1997, Matsuyama et al. 1999). When particles were released from Stn 1, parti- 

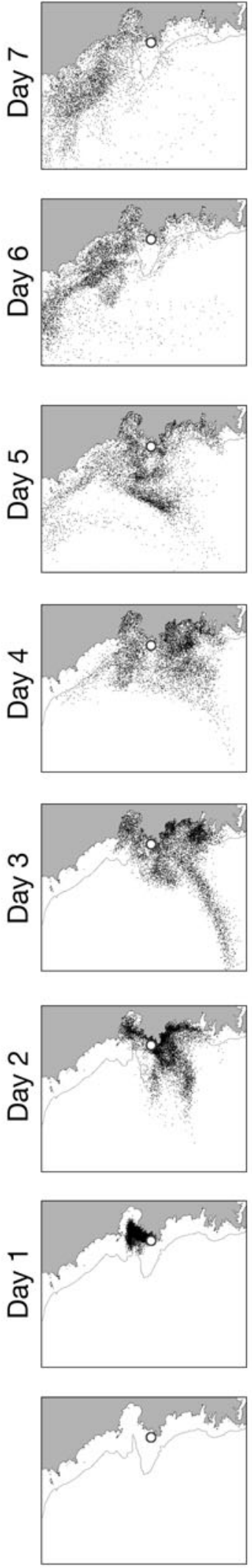

点
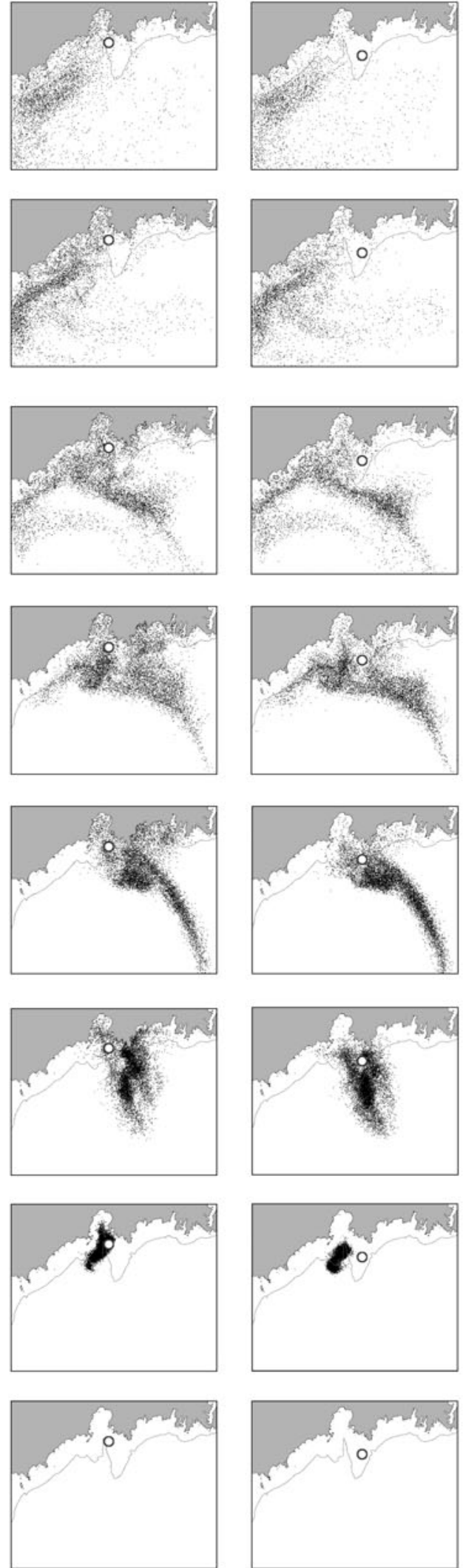

号

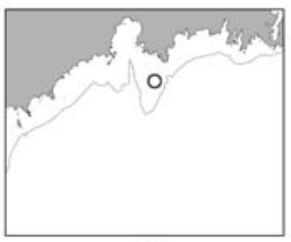

点

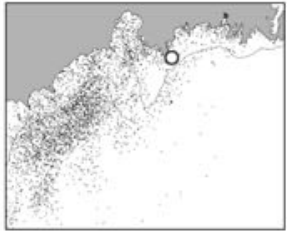

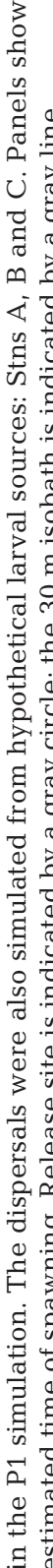
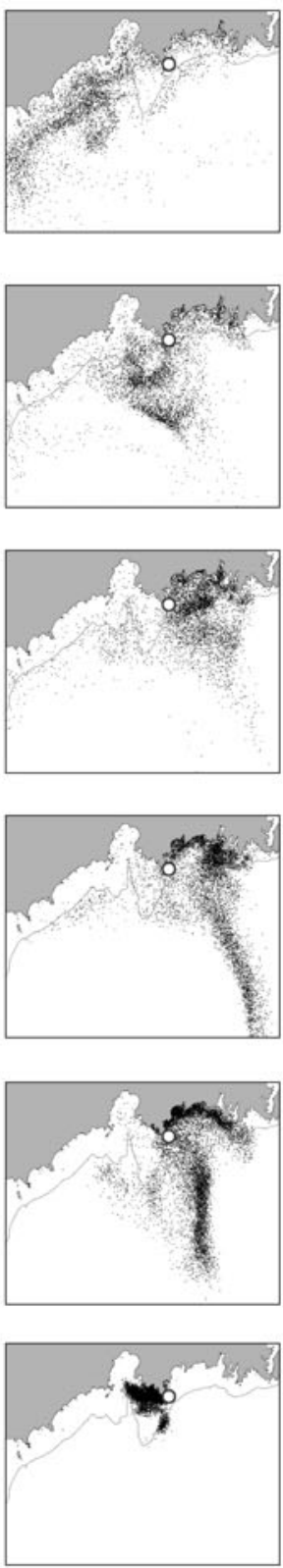

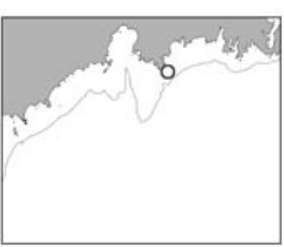

点 $\rightarrow \oplus$

돈도

घี

व

先。

过

으ำ

तथ

즈 중

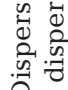

$\dot{0}$

宔 

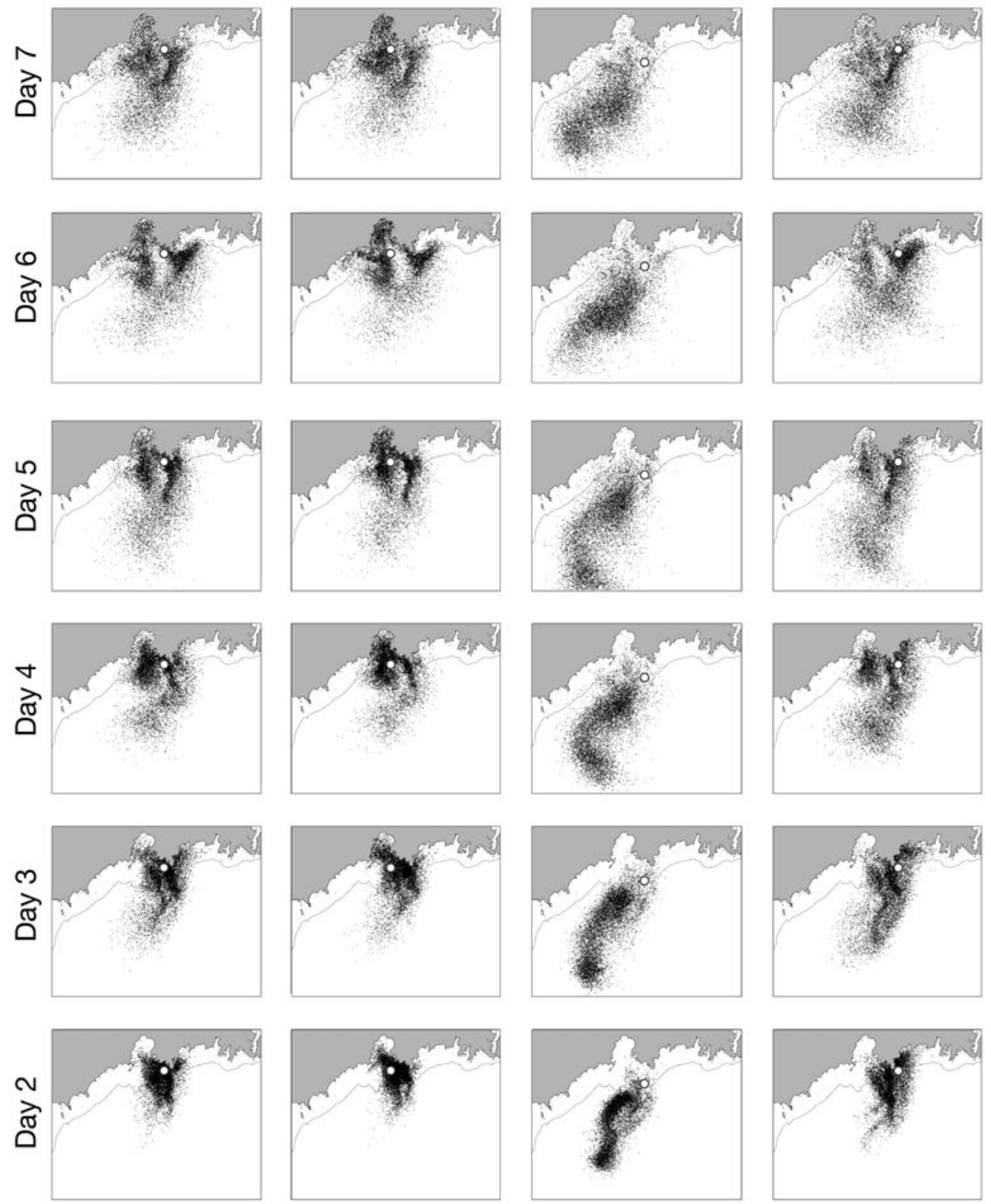

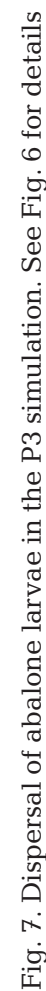
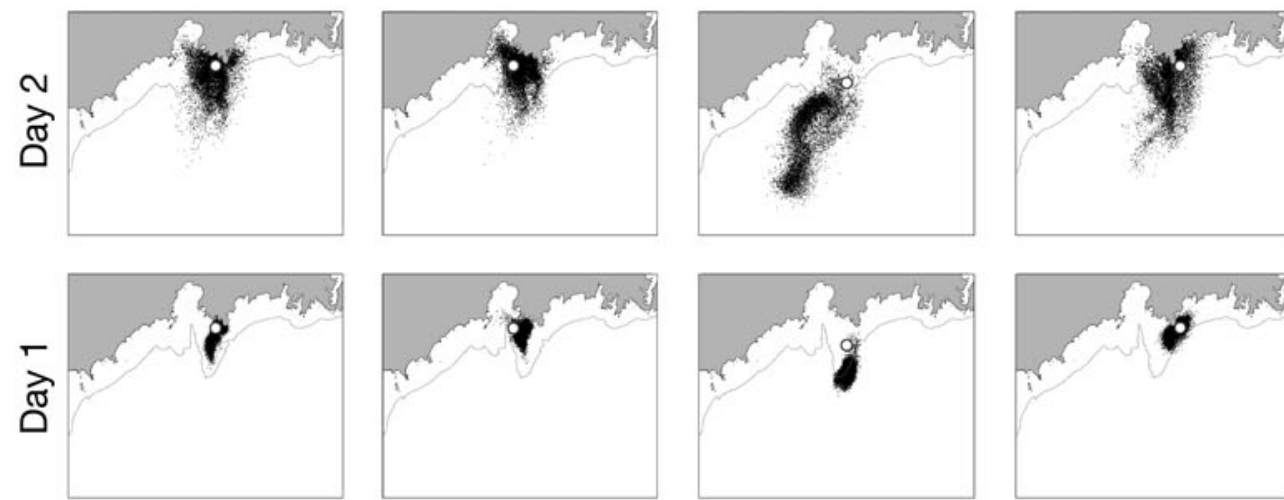

(2)
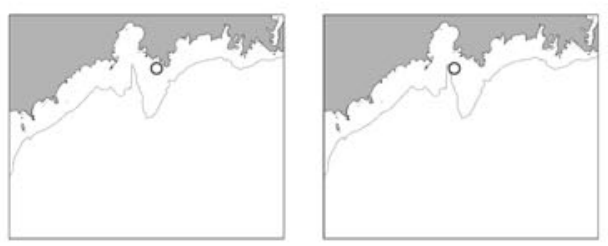

E

点
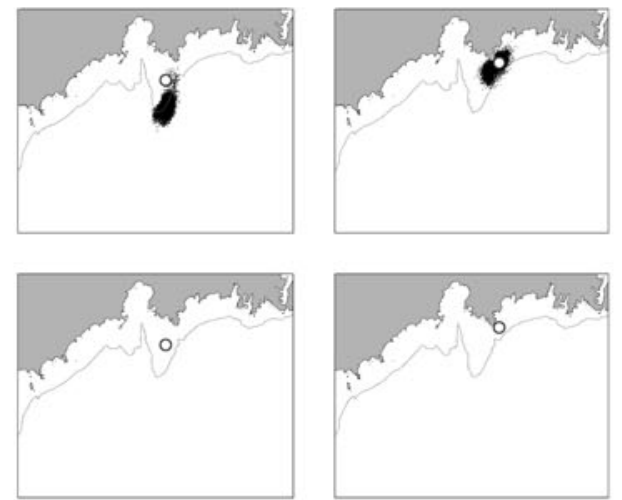

焉

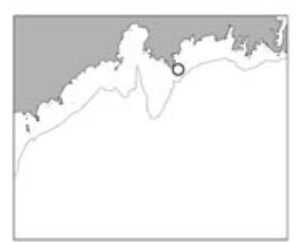

0

क 


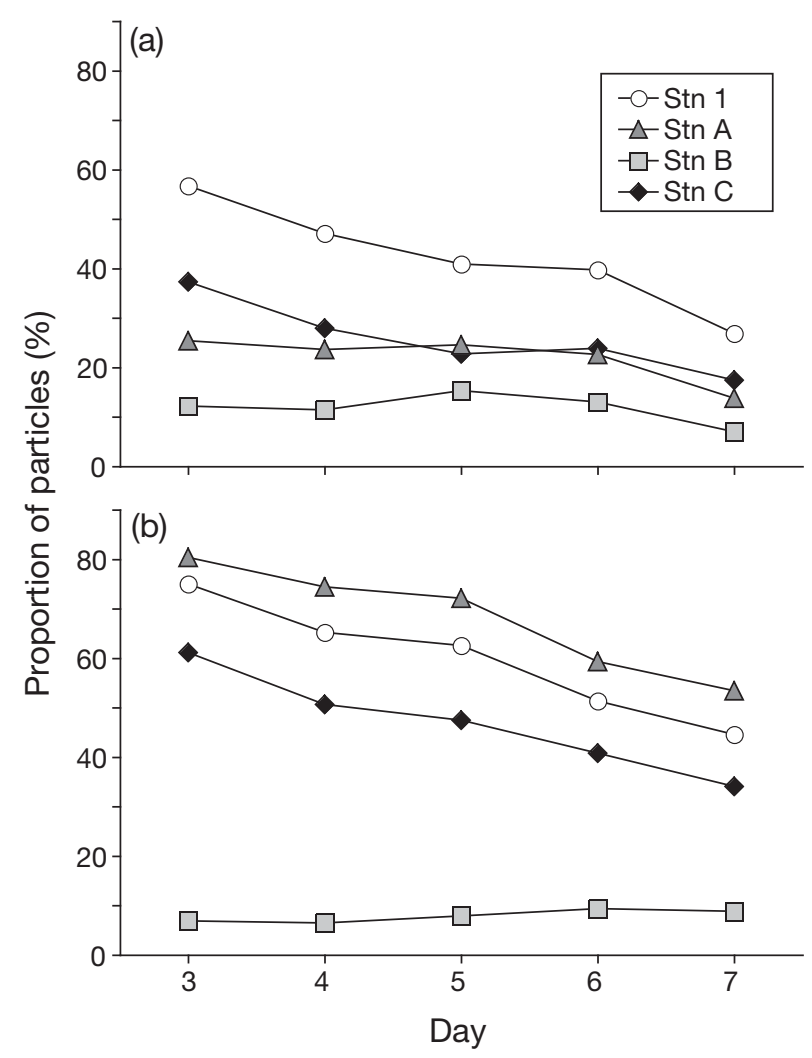

Fig. 8. Proportion of particles, expressed as percentage of total number of released particles, in the shallow area $(\leq 30 \mathrm{~m})$ within the model domain L2 between Day 3 and Day 7 following the estimated time of abalone larval spawning in the (a) P1 and (b) P3 simulations. The proportions are daily averages

cles accumulated along the southern coast of Miura Peninsula in the P1 simulation. This implies that the existing refugium (Stn 1) could be a reproductive source for the southern fishery ground on the east side of Sagami Bay. This accumulation also occurred when particles were released from Stn C. In the P3 simulations for larval dispersal from all particle release sites (Stns 1, A, B and C), the particles slowly dispersed towards the western boundary of the model. Although the particles accumulated from Otawa Bay westward in both P1 and P3 simulations, it was more remarkable in P3. In the P3 simulations, this was especially evident when particles were released from sites near the shore (Stns 1, A, and C). The particle accumulation was also high in the area located southwest of Stn 1. This indicates local larval dispersal from this refugium in calm oceanic conditions. These 2 larval dispersal patterns of the study species resemble those observed for Haliotis discus hannai (Sasaki \& Shepherd 1995), although the scales of larval dispersal are greater in the present study. This suggests a possibility of similar larval dispersal processes in Japanese large abalone species. The sites with high particle accumulations that are up to $30 \mathrm{~m}$ in depth generally have rocky reef seabed characteristics. They can therefore be considered as potential settlement sites for larvae. The accumulation tended to be high near the shore in both simulated periods. These results indicate that there were significant possibilities for larvae to settle in the shallow water if they succeeded in being transported to appropriate substrata.

The model results have important implications for refugium design in this fishery ground. The results indicate that some hydrodynamic conditions and particle release sites were less effective than others in introducing larvae into the areas with adult populations, or at a suitable depth. Since the results of the P3 simulation showed higher proportions of particles in the shallow areas $(\leq 30 \mathrm{~m})$ than those of P1 during the period of settlement competency, the hydrodynamic conditions (i.e. strong currents) in the period of the P1 simulations seem to have been unfavorable. In both periods, Stn B showed a lower transport success. This station is located offshore, and the depths to the north, west, and south of it are $>30 \mathrm{~m}$. This type of location may not be suitable for placing a refugium. The potential settlement sites differed among locations of larval sources. These results suggest that transport success of larvae and settlement sites can be influenced by the intensity of currents and location of the reproductive source.

The larval densities were highly correlated between the refugium (Stn 1) and the fishery ground (Stn 2). Although there were not many adult individuals at Stn 2, the larval densities were relatively high at Stn 2 in the field. Thus, Stn 1 was most likely to be the larval source for this station. For this reason, it is rational to use the ratio of larval densities between Stn 1 and Stn 2 for comparisons with the model results when particles are released at Stn 1, simulating the start of larval dispersal at this site. The correlation between observed and modeled results was low when all sampling stations were taken into account. This could be caused by the limitations of our modeling approach discussed below.

The numerical simulation of larval dispersal is subject to limitations. Constraints may occur due to the simplicity of the model in terms of biological and ecological aspects. Larval swimming behavior and mortality may influence the outcome of their dispersal (Cowen et al. 2000, North et al. 2008, Cowen \& Sponaugle 2009). The results of this study do not reflect the dispersal processes of near-bottom or settling larvae. The daily progress of larval dispersal (Figs. 6 \& 7) can be expected to show how larvae would be transported while they were in the water column. The mortality of larvae may vary temporally and spatially within the study area, yet the details of larval mortality have not been investigated. Larvae are likely to disperse more 

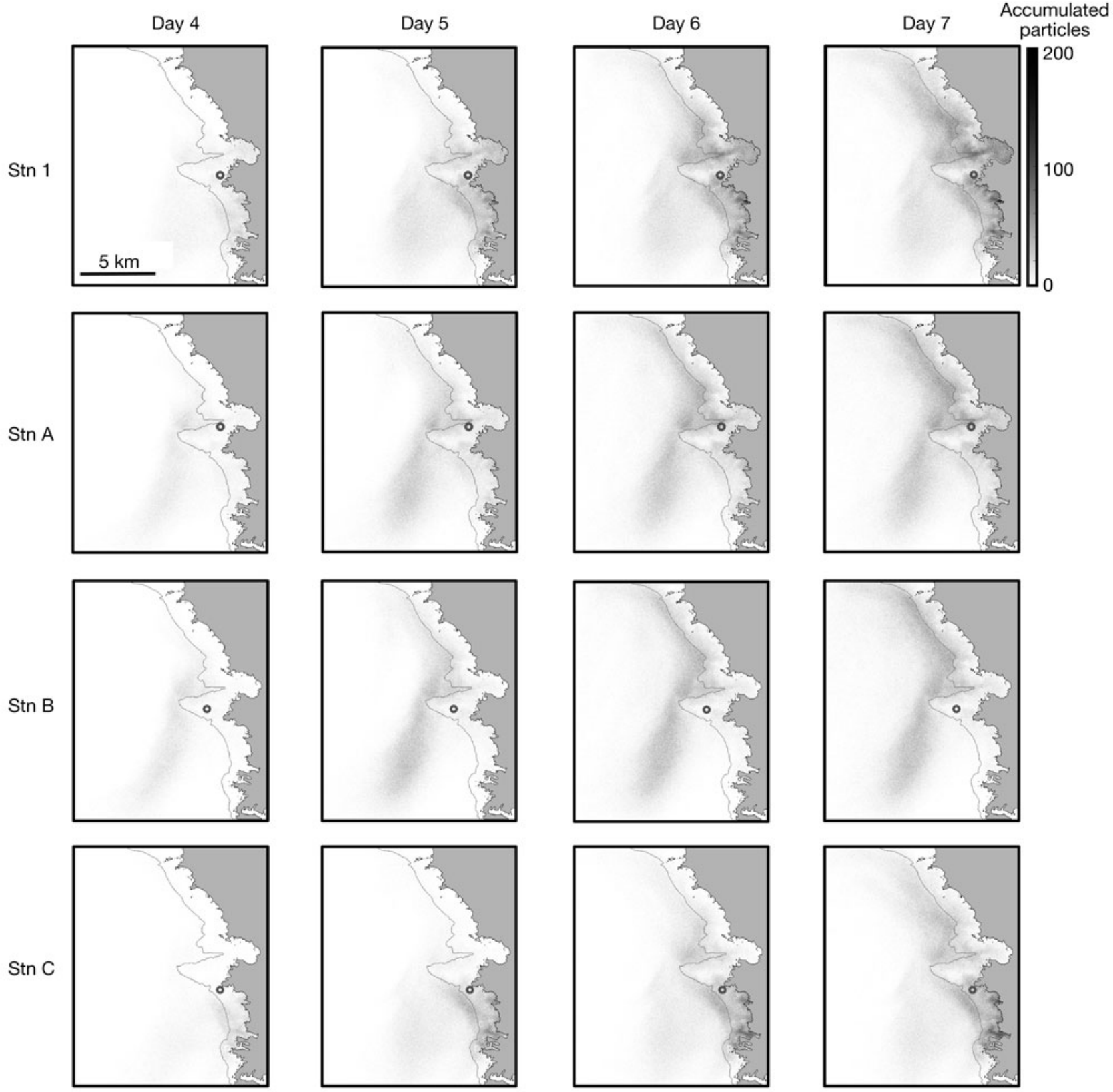

Fig. 9. Potential settlement areas of P1 (first larval density peak) abalone larvae, represented by accumulation of particles during settlement competency. The particles were accumulated on Days 3 to 7 following the estimated time of spawning. The release site (Stn 1, A, B or C) is indicated by a circle; the $30 \mathrm{~m}$ isobath is indicated by a gray line. The bar shows the number of accumulated particles per horizontal grid cell

widely without settling behavior or mortality; therefore, the results provided in this study can be interpreted as maximum larval dispersal and survivorship. Although these simplifications were employed, particle release was based on the larval source and timed according to capture time, eye development and potential spawning cues.

In the simulations of larval dispersal from the existing refugium (Stn 1), the population at this site was assumed as the only larval source in our study site, and particles were only released once. It has been reported that the mean duration of sperm spawning of Haliotis discus discus is $540 \mathrm{~min}$ in a controlled environment (Kikuchi \& Uki 1974). The duration is unknown for the target species in the natural environment; therefore, the release of particles was kept simple in our model. Although the refugium seems most influential in the study area, the observed larval distributions likely included ones from other sources. The incomplete model input of spatial larval production (i.e. particle release 

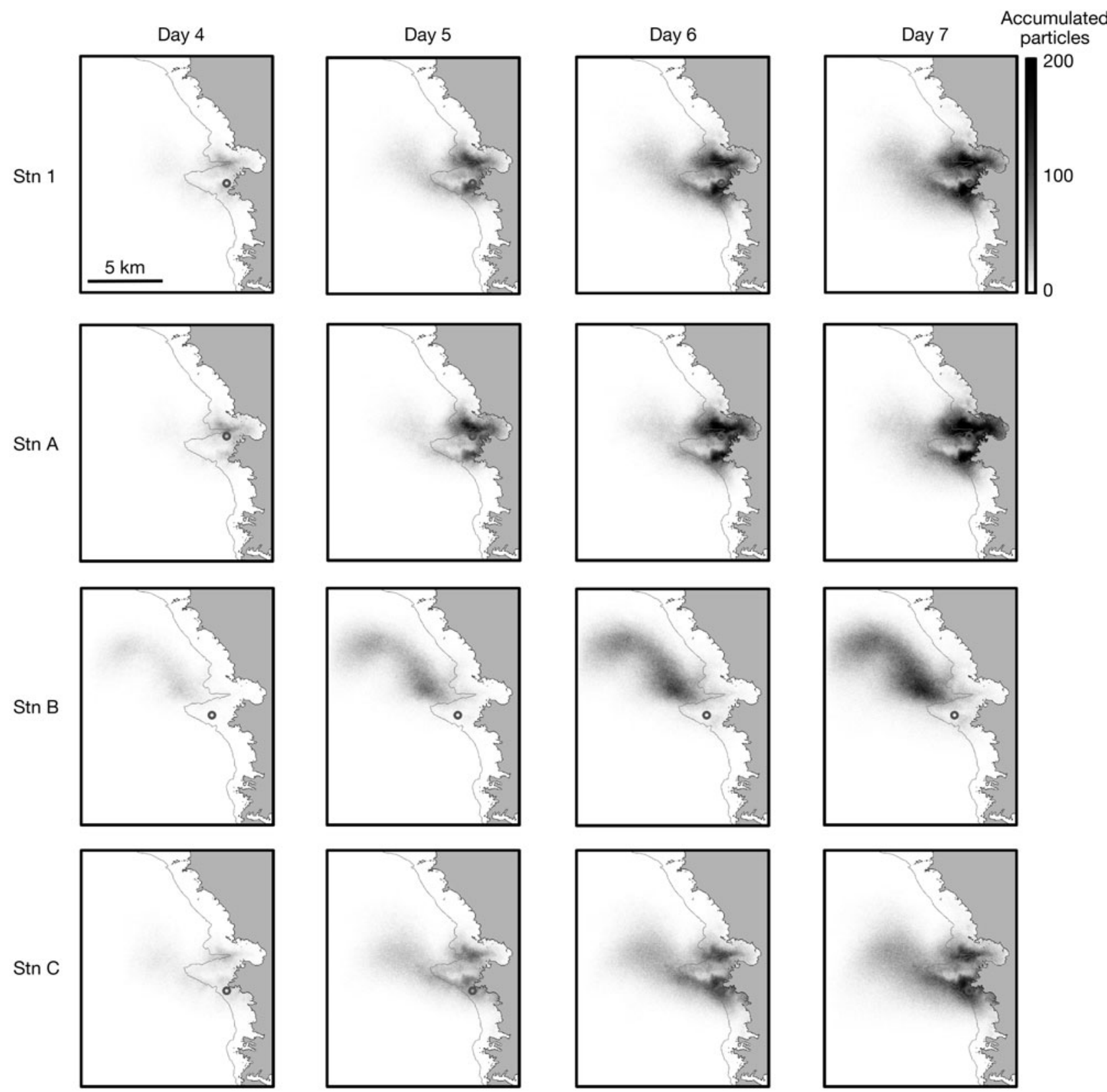

Fig. 10. Potential settlement areas of P3 (third larval density peak) abalone larvae, represented by accumulation of particles during settlement competency. See Fig. 9 for details

sites and number of particles), due to the limited information on the reproductive adult distribution in the field, might have caused the inconsistency between the simulated and the observed distribution of larvae at all sampling sites. This implies that the distribution of reproductive sources should be considered when attempting to reproduce realistic larval distribution. Nonetheless, our study has provided the larval dispersal patterns and settlement sites that are likely to occur for larvae originated from the existing refugium.
The data on larval appearances and environmental factors were not sufficient for elucidating the spawning cues of the study species. The timing of particle release was based on eye spot development of larvae and the assumption that study species spawned when the atmospheric pressure at sea level decreased and the wave height increased. These environmental factors are similar to the spawning cues of Haliotis discus hannai (Sasaki \& Shepherd 1995) and H. diversicolor (Onitsuka et al. 2007). However, the spawning cues of 
the study species need to be clarified with sufficient data, and this would enable us to determine the timing of particle release more precisely. In our model, the shallow area $(\leq 30 \mathrm{~m})$ was used to estimate the transport success of larvae; the locations of favorable substrata for larval settlement were not included, since it was not possible to locate the substrata with CCAthe surface of which has the inducer causing larval settlement (Morse \& Morse 1984) — in the entire area covered by the model domain L2. Therefore, our simulations focused only on the settlement depth. Further biological and ecological investigations on these abalone species are crucial to improve our particletracking model.

It was not clear whether the population in Stn 1 was contributing to the regeneration of the natural population because larvae could be transported to inappropriate settlement areas. However, the results of the particle-tracking experiments showed that 27 to $57 \%$ and 45 to $75 \%$ of the larvae from Stn 1 were inside the shallow area $(\leq 30 \mathrm{~m})$ during the period of settlement competency in the P1 and P3 simulations, respectively (Fig. 8). These results indicate that the larvae could be recruited to these areas if they can settle on the favorable substrata. Among all reproductive sources tested, the location of Stn 1 was the most suitable in larval transport success. If the larval dispersal is causing the low abundance of our target species at the study site, the transport success of larvae from Stn 1, as indicated by the model results, may not be sufficient for the recovery of the population. The transport success can be even lower in cases of high larval mortality. Interannual differences in transport success need to be investigated to determine the influence of larval dispersal on the low abundance of the study species.

The modeling of larval dispersal is a necessary step in the design of abalone refugia in fishery grounds. The model could be used for predicting the location of potential settlement sites, as well as for evaluation and selection of the areas for harvest refugia as larval sources. However, care must be taken when deciding where refugia should be located. The predicted larval settlement sites should be carefully investigated, since mortality is high for a few weeks post-settlement (Sasaki \& Shepherd 1995) and factors such as food availability (Takami et al. 2000, Sasaki \& Shepherd 2001), depth (McShane \& Naylor 1995), and predation (reviewed by Shepherd \& Breen 1992) could affect larval survival. Substrata should be carefully assessed in regard to feeding and growth during the postlarval period (reviewed by Kawamura et al. 1998). These factors may be related to the persistent low catch of our target abalone species in the study area. The low catch may also be influenced by limited recruitment due to the reduction in adult densities (Kawamura et al.
2002). Although suitable substrata and postlarval survival must be considered, the effectiveness of restoration attempts may be enhanced by introducing artificial seeds into the areas suggested by the model results. The method and model developed in the present study could be used to evaluate harvest refugia and to identify effective locations for reproductive sources on the basis of larval dispersal. Metapopulation dynamics are crucial to restocking of exploited marine populations (Lipcius et al. 2008). Although this study focuses on the larval supply from the main refugium, the use of metapopulation connectivity between refugia may enhance the sustainability of populations, and it may be more effective for replenishment of depleted populations.

Acknowledgements. We thank Dr. T. Imai and Mr. M. Terui of the Kanagawa Prefectural Fisheries Technology Center, and Mr. N. Takiguchi of the Kanagawa Prefectural Government for providing valuable information. We also thank Mr. Y. Kajigaya for providing data on wave height grade and boat operation, Ms. M. Sato for help in sorting larvae, and Dr. K. Itoh for providing the bathymetry data. We gratefully acknowledge Mr. H. Nagae, Drs. S. Itoh, H. Kim, T. Takahashi and our colleagues for their assistance with fieldwork and simulations.

\section{LITERATURE CITED}

Breen PA, Adkins BE (1980) Spawning in a British Columbia population of northern abalone, Haliotis kamtschatkana. Veliger 23:177-179

Brown CA, Holt SA, Jackson GA, Brooks DA, Holt GJ (2004) Simulating larval supply to estuarine nursery areas: How important are physical processes to the supply of larvae to the Aransas Pass Inlet? Fish Oceanogr 13:181-196

> Cowen RK, Sponaugle S (2009) Larval dispersal and marine population connectivity. Annu Rev Mar Sci 1:443-466

> Cowen RK, Lwiza KMM, Sponaugle S, Paris CB, Olson DB (2000) Connectivity of marine populations: Open or closed? Science 287:857-859

Epifanio CE (1995) Transport of blue crab (Callinectes sapidus) larvae in the waters off mid-Atlantic states. Bull Mar Sci 57:713-725

Hamaguchi M, Sasaki M, Horii T, Kiyomoto S and others (2006) Development of a discrimination methods by using molecular and monoclonal antibodies techniques for Haliotis discus discus, $H$. madaka and $H$. gigantea during their early life stages. Bull Fish Res Agency (Suppl 5):75-83 (in Japanese with English abstract)

Hashimoto S, Horimoto N, Yamaguchi Y, Ishimaru T, Saino T (2005) Relationship between net and gross primary production in the Sagami Bay, Japan. Limnol Oceanogr 50: 1830-1835

Hayashi I (1983) Larval shell morphology of some Japanese Haliotids for the identification of their veliger larvae and early juveniles. Venus 42:49-58 (in Japanese with English abstract)

> Hinrichsen HH, Bottcher U, Koster FW, Lehmann A, St John MA (2003) Modelling the influences of atmospheric forcing conditions on Baltic cod early life stages: distribution and drift. J Sea Res 49:187-201

Horii T, Kurogi H, Kajigaya Y, Takiguchi N, Hamaguchi M 
(2006) A note on differences of species composition between swimming larvae and post-larvae of abalone, Haliotidae, in the coast of Sagami Bay. Bull Fish Res Agency (Suppl 5):85-89 (in Japanese with English abstract)

Ino T (1952) Biological studies on the propagation of Japanese abalone (genus Haliotis). Bull Tokai Regional Fish Res Lab 5:1-102 (in Japanese with English abstract)

Itosu C, Miki M (1983) Field observation of wave-induced circulation in ormer fishing ground. Bull Jpn Soc Scientific Fisheries 49:339-346

Kasai A, Sakamoto W, Mitsunaga Y, Yamamoto S (2000) Behaviour of immature yellowtails (Seriola quinqueradiata) observed by electronic data-recording tags. Fish Oceanogr 9:259-270

Kawamura T, Roberts RD, Takami H (1998) A review of the feeding and growth of postlarval abalone. J Shellfish Res 17:615-625

Kawamura T, Takami H, Saido T (2002) Early life ecology of abalone Haliotis discus hannai in relation to recruitment fluctuations. Fish Sci 68(Suppl. 1):230-233

Kawamura T, Roberts RD, Takami H (2005) Importance of periphyton in abalone culture. In: Azim ME, Verdegem MCJ, Dam AAV, Beveridge MCM (eds) Periphyton: ecology, exploitation and management. CAB International Publishing, Wallingford, p 269-284

Kikuchi S, Uki N (1974) Technical study on artificial spawning of abalone, genus Haliotis V. relation between water temperature and advancing sexual maturity of Haliotis discus Reeve. Bull Tohoku Regional Fish Res Lab 34:77-85 (in Japanese with English abstract)

Kim H, Kimura S, Sugimoto T (2007) Transport of jack mackerel (Trachurus japonicus) larvae inferred from the numerical experiment in the East China Sea. Bull Jpn Soc Fish Oceanogr 71:9-17

Kundu PK (1976) Ekman veering observed near ocean bottom. J Phys Oceanogr 6:238-242

> Lewis JK, Shulman I, Blumberg AF (1998) Assimilation of Doppler radar current data into numerical ocean models. Cont Shelf Res 18:541-559

Lipcius RN, Stockhausen WT, Eggleston DB (2001) Marine reserves for Caribbean spiny lobster: empirical evaluation and theoretical metapopulation recruitment dynamics. Mar Freshw Res 52:1589-1598

Lipcius RN, Eggleston DB, Schreiber SJ, Seitz RD and others (2008) Importance of metapopulation connectivity to restocking and restoration of marine species. Rev Fish Sci 16:101-110

> Matsumoto K, Takanezawa T, Ooe M (2000) Ocean tide models developed by assimilating TOPEX/POSEIDON altimeter data into hydrodynamical model: a global model and a regional model around Japan. J Oceanogr 56:567-581

Matsuyama M, Iwata S, Nagamatsu H (1997) Kyucho in Sagami Bay induced by Typhoon 8818. J Oceanogr 53: 199-205

- Matsuyama M, Ishidoya H, Iwata S, Kitade Y, Nagamatsu H (1999) Kyucho induced by intrusion of Kuroshio water in Sagami Bay, Japan. Cont Shelf Res 19:1561-1575

McShane PE, Naylor JR (1995) Depth can affect postsettlement survival of Haliotis Iris (Mollusca, Gastropoda). J Exp Mar Biol Ecol 187:1-12

McShane PE, Black KP, Smith MG (1988) Recruitment processes in Haliotis rubra (Mollusca: Gastropoda) and regional hydrodynamics in southeastern Australia imply localized dispersal of larvae. J Exp Mar Biol Ecol 124: 175-203

> Morse ANC, Morse DE (1984) Recruitment and metamorphosis of Haliotis larvae induced by molecules uniquely avail- able at the surfaces of crustose red algae. J Exp Mar Biol Ecol 75:191-215

Najmudeen TM, Victor ACC (2004) Seed production and juvenile rearing of the tropical abalone Haliotis varia Linnaeus 1758. Aquaculture 234:277-292

North EW, Schlag Z, Hood RR, Li M, Zhong L, Gross T, Kennedy VS (2008) Vertical swimming behavior influences the dispersal of simulated oyster larvae in a coupled particle-tracking and hydrodynamic model of Chesapeake Bay. Mar Ecol Prog Ser 359:99-115

Onitsuka T, Kawamura T, Horii T, Takiguchi N, Takami H, Watanabe Y (2007) Synchronized spawning of abalone Haliotis diversicolor triggered by typhoon events in Sagami Bay, Japan. Mar Ecol Prog Ser 351:129-138

Prince JD, Sellers TL, Ford WB, Talbot SR (1987) Experimental evidence for limited dispersal of haliotid larvae (genus Haliotis; Mollusca: Gastropoda). J Exp Mar Biol Ecol 106: 243-263

Prince JD, Sellers TL, Ford WB, Talbot SR (1988) Confirmation of a relationship between the localized abundance of breeding stock and recruitment for Haliotis rubra Leach (Mollusca: Gastropoda). J Exp Mar Biol Ecol 122:91-104

Roberts R (2001) A review of settlement cues for larval abalone (Haliotis spp.). J Shellfish Res 20:571-586

> Roberts RD, Lapworth C (2001) Effect of delayed metamorphosis on larval competence, and post-larval survival and growth, in the abalone Haliotis iris Gmelin. J Exp Mar Biol Ecol 258:1-13

Sasaki R, Shepherd SA (1995) Larval dispersal and recruitment of Haliotis discus hannai and Tegula spp. on Miyagi coasts, Japan. Mar Freshw Res 46:519-529

Sasaki R, Shepherd SA (2001) Ecology and post-settlement survival of the ezo abalone, Haliotis discus hannai, on Miyagi Coasts, Japan. J Shellfish Res 20:619-626

Seki T, Kan-no H (1977) Synchronized control of early life in the abalone, Haliotis discus hannai INO, Haliotidae, Gastropoda. Bull Tohoku Regional Fish Res Lab 38:143-153 (in Japanese with English abstract)

Seki T, Kan-no H (1981) Observations on the settlement and metamorphosis of the veliger of the Japanese abalone, Haliotis discus hannai Ino, Haliotidae, Gastropoda. Bull Tohoku Regional Fish Res Lab 42:31-39 (in Japanese with English abstract)

Shanks AL, Largier J, Brink L, Brubaker J, Hooff R (2000) Demonstration of the onshore transport of larval invertebrates by the shoreward movement of an upwelling front. Limnol Oceanogr 45:230-236

Shanks AL, Grantham BA, Carr MH (2003) Propagule dispersal distance and the size and spacing of marine reserves. Ecol Appl 13(Suppl):159-169

Shepherd SA, Breen PA (1992) Mortality in abalone: its estimation, variability and causes. In: Shepherd SA, Tegner MJ, Proo SAGD (eds) Abalone of the world: biology, fisheries and culture. Fishing News Books, Oxford

Shepherd SA, Brown LD (1993) What is an abalone stock? implications for the role of refugia in conservation. Can J Fish Aquat Sci 50:2001-2009

Shepherd SA, Lowe D, Partington D (1992) Studies on southern Australian abalone (genus Haliotis) XIII: larval dispersal and recruitment. J Exp Mar Biol Ecol 164:247-260

Shulman I, Wu CR, Lewis JK, Paduan JD and others (2002) High resolution modeling and data assimilation in the Monterey Bay area. Cont Shelf Res 22:1129-1151

> Stephens SA, Broekhuizen N, Macdiarmid AB, Lundquist CJ, McLeod L, Haskew R (2006) Modelling transport of larval New Zealand abalone (Haliotis iris) along an open coast. Mar Freshw Res 57:519-532 
Stockhausen WT, Lipcius RN (2001) Single large or several small marine reserves for the Caribbean spiny lobster? Mar Freshw Res 52:1605-1614

Takami H, Kawamura T, Yamashita Y (2000) Starvation tolerance of newly metamorphosed abalone Haliotis discus hannai. Fish Sci 66:1180-1182

Takami H, Kawamura T, Yamashita Y (2002) Effects of delayed metamorphosis on larval competence, and postlarval survival and growth of abalone Haliotis discus hannai. Aquaculture 213:311-322

Takami H, Oshino A, Sasaki R, Fukazawa H, Kawamura T (2006) Age determination and estimation of larval period in field caught abalone (Haliotis discus hannai Ino 1953) larvae and newly metamorphosed post-larvae by counts of radular teeth rows. J Exp Mar Biol Ecol 328:289-301

Takiguchi N (2002) Population dynamics of abalone in coastal area of Kanagawa, Japan. Kaiyo Monthly 34:482-488 (in Japanese)

Tanaka K, Tanaka T, Ishida O, Ohba T (1986) On the distrib-

Editorial responsibility: Romuald Lipcius,

Gloucester Point, Virginia, USA ution of swimming and deposited larvae of nursery ground of abalone at the southern coast of Chiba Prefecture. Bull Jpn Soc Scientific Fisheries 52:1525-1532 (in Japanese with English abstract)

Tegner MJ, Butler RA (1985) Drift-Tube study of the dispersal potential of green abalone (Haliotis fulgens) larvae in the southern California Bight: implications for recovery of depleted populations. Mar Ecol Prog Ser 26:73-84

Tomita K, Tajima Ki, Kudo K (1977) Morphological observation of the veliger and the creeping larvae of an abalone, Haliotis discus hannai, from Rebun Island in the NorthWestern Hokkaido. Sci Rep Hokkaido Fish Exp Stn 19:13-19 (in Japanese with English abstract)

Wallace SS (1999) Evaluating the effects of three forms of marine reserve on northern abalone populations in British Columbia, Canada. Conserv Biol 13:882-887

Yano I, Ogawa Y (1977) Effects of light, temperature and hydrostatic pressure on vertical distribution of ablone larvae, Haliotis gigantea. Bull Tokai Regional Fish Res Lab 91: $19-27$

Submitted: November 24, 2008; Accepted: April 28, 2009 Proofs received from author(s): July 12, 2009 